\title{
LA-UR-12-23208
}

Approved for public release; distribution is unlimited.

Title:

Some General Themes in Catalysis at LANL

Author(s): $\quad$ Gordon, John C.

Intended for: $\quad$ Slides for LANL managers

Disclaimer:

Los Alamos National Laboratory, an affirmative action/equal opportunity employer,is operated by the Los Alamos National

Security, LLC for the National NuclearSecurity Administration of the U.S. Department of Energy under contract DE-AC52-06NA25396. By approving this article, the publisher recognizes that the U.S. Government retains nonexclusive, royalty-free license to publish or reproduce the published form of this contribution, or to allow others to do so, for U.S. Government purposes.

Los Alamos National Laboratory requests that the publisher identify this article as work performed under the auspices of the

U.S. Departmentof Energy. Los Alamos National Laboratory strongly supports academic freedom and a researcher's right to publish; as an institution, however, the Laboratory does not endorse the viewpoint of a publication or guarantee its technical correctness. 


\section{Some General Themes in Catalysis at LANL}

- Storage and release of energy within chemical bonds (e.g. $\mathrm{H}_{2}$ storage in and release from covalent bonds, $\mathrm{N}_{2}$ functionalization, $\mathrm{CO}_{2}$ functionalization, $\mathrm{H}_{2}$ oxidation/evolution, $\mathrm{O}_{2}$ reduction/evolution).

- Can we control the chemistry of reactive substrates to effect energy relevant transformations in non-traditional media (e.g. can we promote C-C couplings, dehydrations, or hydrogenations in water under relatively mild conditions)?

- Can we supplant precious metal or rare earth catalysts to effect these transformations, by using earth abundant metals/elements instead? Can we use organocatalysis and circumvent the use of metals completely?

- Can we improve upon existing rare earth catalyst systems (e.g. in rare earth oxides pertinent to fluid cracking or polymerization) and reduce amounts required for catalytic efficacy? 


\section{Some Recent Examples from LANL}

A. Upgrading of (Non-Food Based) Biomass Derived Molecules into Fuels

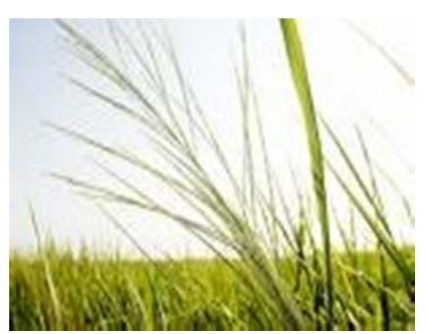

switchgrass

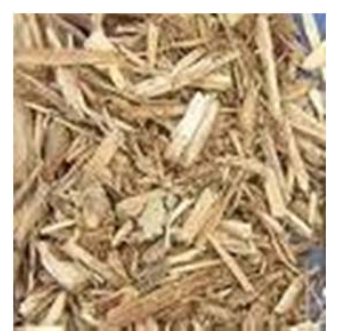

wood residue

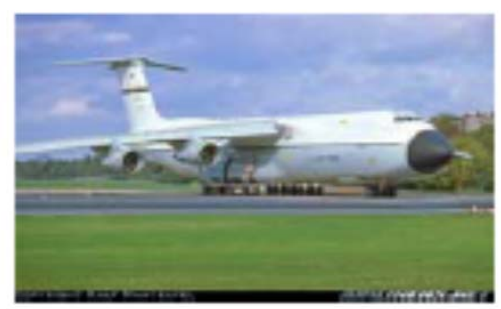

High Energy Density $C_{8}-C_{15}$ Fuels

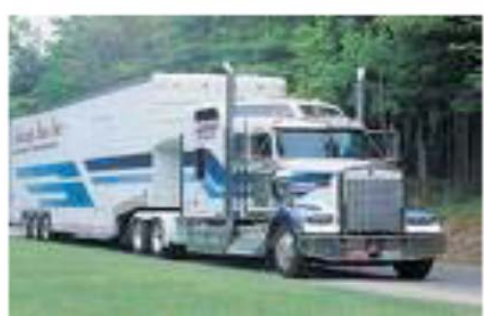

Carbohydrates can be accessed from non-food based biomass sources such as woody residues and switchgrass. After extracted from the plant source, our goal is to upgrade these classes of molecules into useful fuels. 


\section{Converting Sugars and Derivatives into Hydrocarbons}

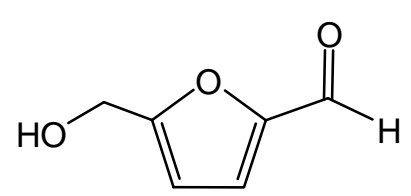

Hydroxymethylfurfural (HMF)

available from fructose, glucose, cellulose

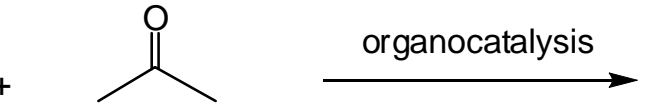

acetone

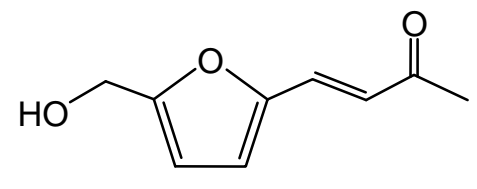

Hydrodeoxygenation catalysis

Approach generally applicable to synthesis of hydrocarbons in $\mathrm{C}_{8}-\mathrm{C}_{15}$ range

"Method of Carbon Chain Extension using Novel Aldol Reaction", US patent application 20110040110, filed August 17 ${ }^{\text {th }}, 2009$.

"Compounds and Methods For the Production of Long Chain Hydrocarbons From Biological Sources", $1^{\text {st }}$ US Provisional Patent (Application No. 61/534,496), filed September 14th, 2011; $2^{\text {nd }}$ Provisional Patent (Application No. 61/669,775 ), filed July $10^{\text {th }}, 2012$.

We have also demonstrated the production of hydrocarbons directly from oligosaccharides:

"One Step Conversion of Oligomeric Starch or Cellulose to Single $\mathrm{C}_{10}$ or $\mathrm{C}_{11}$ Carbon Chains Furans and their Conversion to Fuel Hydrocarbons", US provisional patent application 61/669,980, filed July 10"th 2012. 


\section{$\mathbf{N}_{2}$ Functionalization Chemistry}

The industrial production of ammonia $\left(\mathrm{NH}_{3}\right)$ from dinitrogen $\left(\mathrm{N}_{2}\right)$ and hydrogen $\left(\mathrm{H}_{2}\right)$ is integral to U.S. and world-wide food supplies

- Responsible for $\mathrm{ca} .50 \%$ of the nitrogen in our bodies

- $10^{8}$ tons/year of $\mathrm{NH}_{3}$ is produced

- $\quad>1 \%$ of the world's total energy output is consumed by this single process

While the reaction is thermodynamically favorable $\left(\Delta \mathrm{H}^{0}=-45.2 \mathrm{~kJ} \mathrm{~mol}^{-1} \mathrm{NH}_{3}\right)$, the large activation barrier $\left(\mathrm{E}_{\mathrm{A}}=\right.$ $\left.420 \mathrm{~kJ} \mathrm{~mol}^{-1}\right)$ is responsible for the energy-intensive reaction conditions ( $\sim 50{ }^{\circ} \mathrm{C}$ and $\left.\sim 200 \mathrm{~atm}\right)$

Impact of catalysis under mild conditions: Meaningful decrease in the collateral effects of energy generation

\section{Approach}

- Develop an Fe-based catalyst (Global scale considerations)

- Cooperative weaking of the $\mathrm{N}-\mathrm{N}$ bond in order the decrease the number of intermediates (and possible decomposition pathways)

- Develop an $\mathrm{Fe}(0) / \mathrm{Fe}(\mathrm{III})$ reduction cycle

John Gordon, Neil Henson, Fran Rein, Nathan Smythe, et.al.

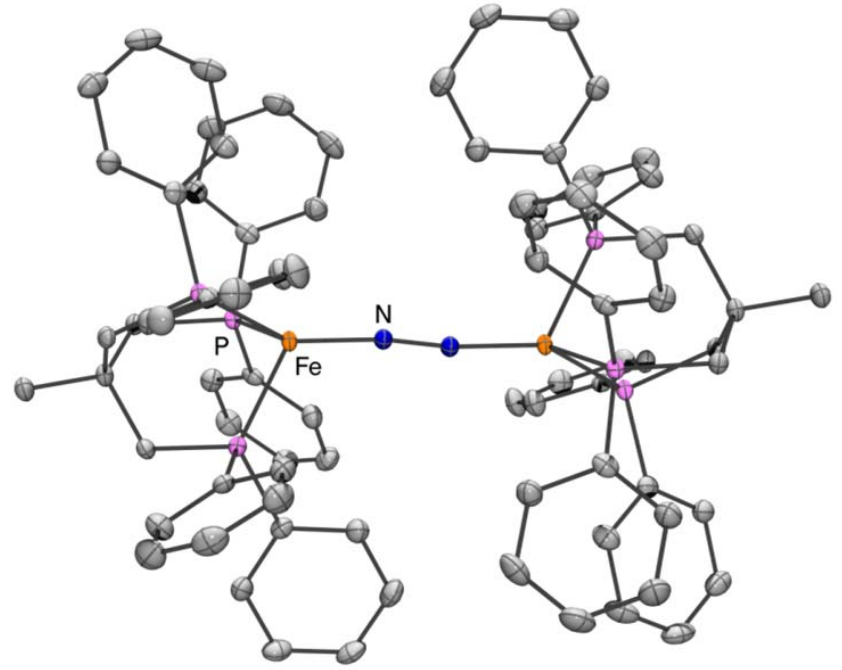

$\mathrm{N}-\mathrm{N}$ bond: $1.21,1.22 \AA$ (2 molecules/unit cell) free $\mathrm{N}_{2}: 1.10 \AA$

$v_{\mathrm{NN}}=1501 \mathrm{~cm}^{-1}$, free $\mathrm{N}_{2}: 2331 \mathrm{~cm}^{-1}$ 


\section{Conversion of $\mathrm{CO}_{2}$ into $\mathrm{MeOH}$}

- Current research (Stephan et al., Denning et al.) shows conversion of $\mathrm{CO}_{2}$ to $\mathrm{MeOH}$ noncatalytically at RT with frustrated Lewis pairs (FLPs).

- FLPs destroyed on $\mathrm{MeOH}$ release on $\mathrm{H}_{2} \mathrm{O}$ addition.

- Our goal - develop air/water/acid tolerant FLPs to bind $\mathrm{CO}_{2}$ to facilitate catalytic conversion of $\mathrm{CO}_{2}$ to $\mathrm{MeOH}$.
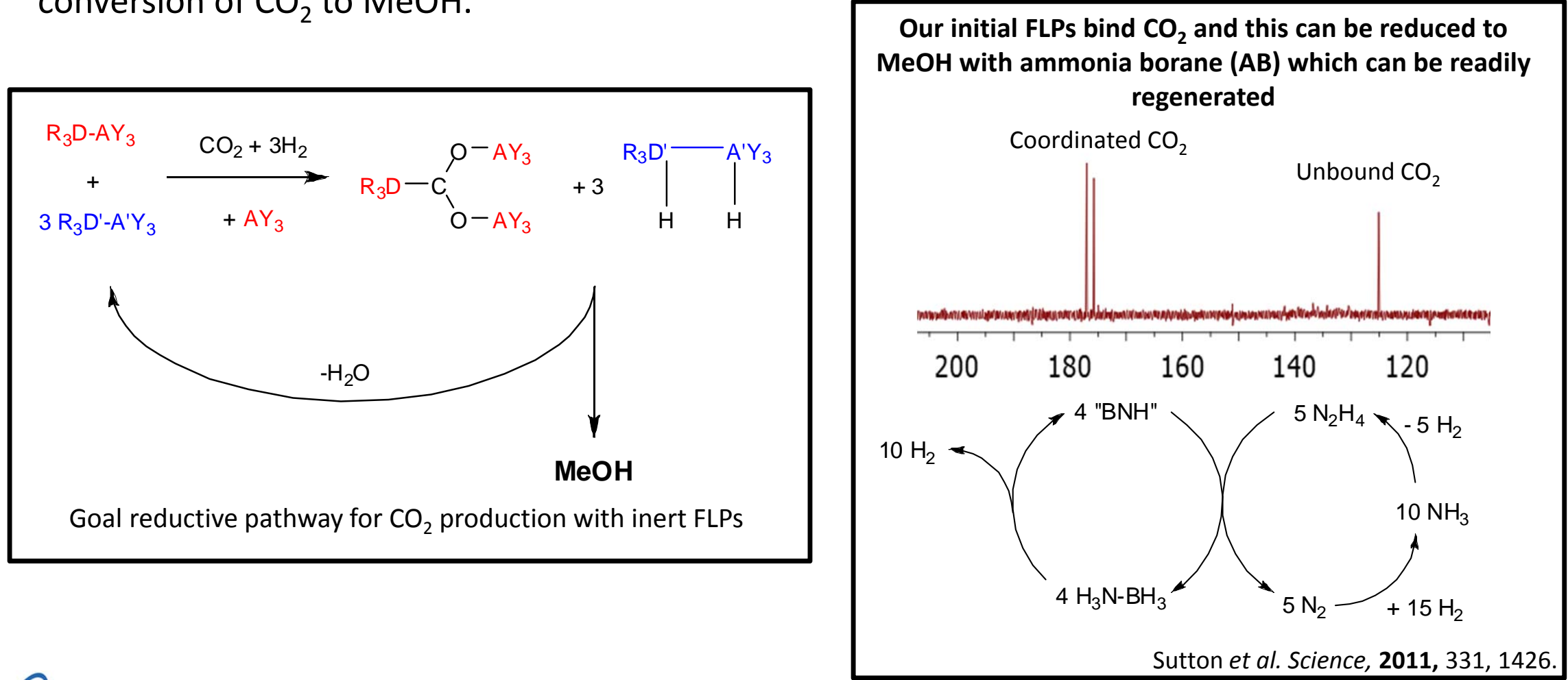

Los Alamos

Andy Sutton, Nathan Smythe, et.al. 


\section{Base Metal Hydrogenations}

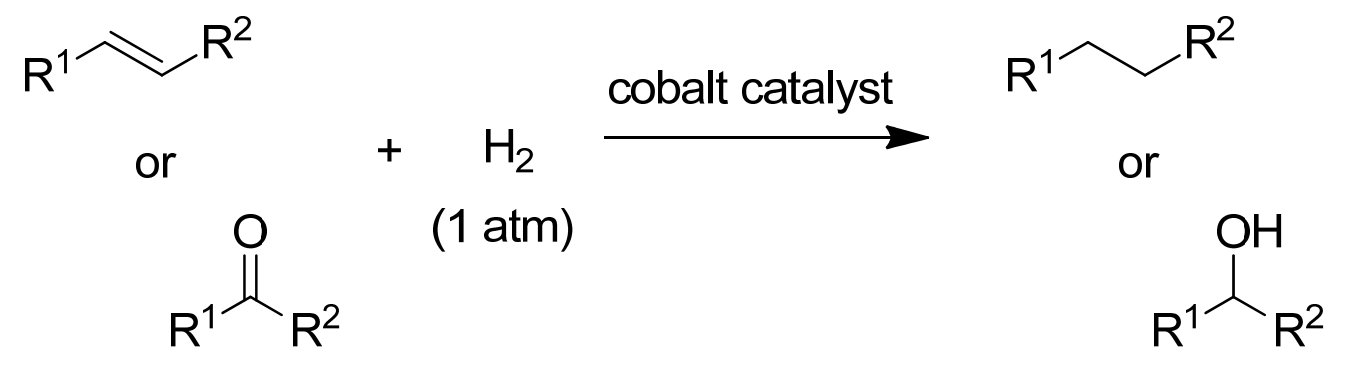

Cobalt catalyst hydrogenates alkenes, ketones, and aldehydes

- Maintains activity in the presence of water:

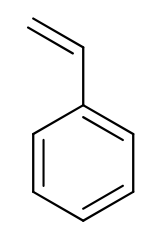

$+$

$\mathrm{H}_{2} \mathrm{O}(10 \mathrm{~mol} \%)$

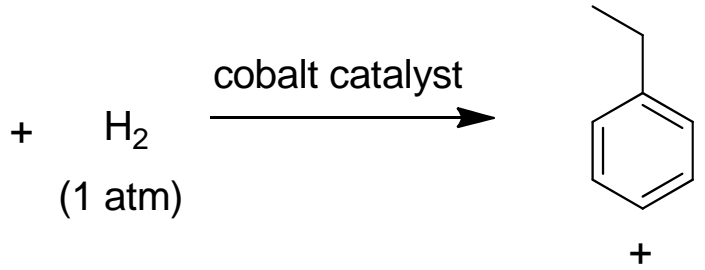

$\mathrm{H}_{2} \mathrm{O}(10 \mathrm{~mol} \%)$
Susan Hanson, et. al. 


\section{Non-Precious Metal Oxygen Reduction Catalysts for Fuel Cells}
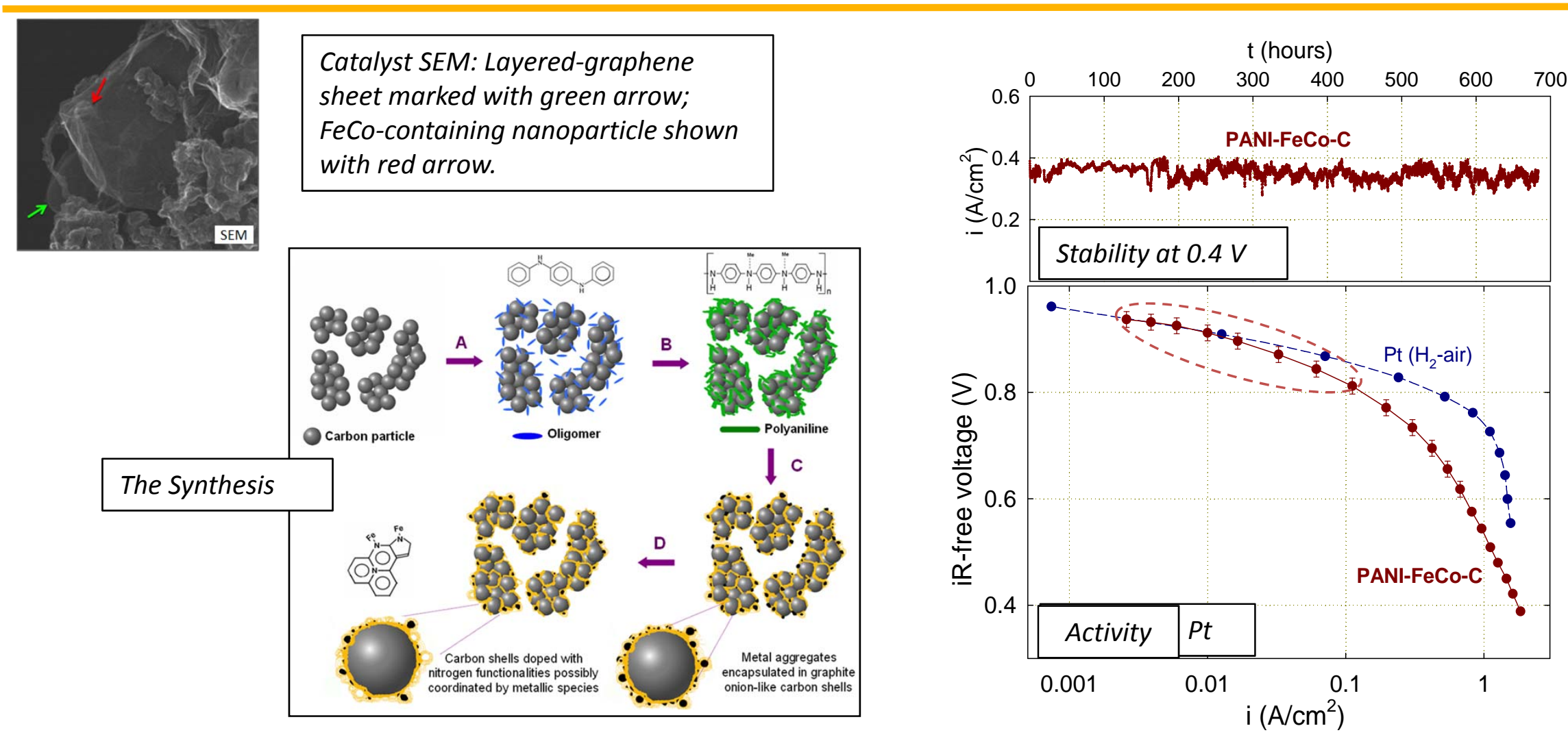

-Pt-based fuel cell catalysts currently representing ca. $25 \%$ of the entire fuel cell system cost

-Graphene-rich polyaniline-derived catalysts, e.g. PANI-FeCo-C, combining for the first time: (a) high activity (close to that of Pt); (b) high stability; (c) excellent selectivity $\left(\mathrm{O}_{2}\right.$ reduction to $\mathrm{H}_{2} \mathrm{O}$ not $\left.\mathrm{H}_{2} \mathrm{O}_{2}\right)$; and (d) low cost a major progress in polymer electrolyte fuel cell technology 


\section{Thin Rare Earth Oxide (REO) Films for Critical Material Needs}

\section{Challenge/Motivation}

- Improve understanding of f-electron contributions to physical and chemical properties of rare earth oxides (REO)Materials Genome

- Materials optimization through control of microstructure in thin film REO catalyst materials ( $\mathrm{Nd}, \mathrm{Pr}, \mathrm{Ce}, \mathrm{La}$ )

\section{Goal/Deliverable}

- $\quad$ Predict and control REO properties using advanced modeling, spectroscopy, and synthesis

- Optimized REO thin film catalysts that reduce dependence on rare earth elements

\section{Approach:}

- High quality epitaxial thin films of REO using polymer assisted deposition technique

- Leverage our actinide oxide successes in synthesis, structure-property control, and theory

- Band gap, XRD, TEM, electronic structure measurements (ARPES), XAFS and XANES, including in-situ measurements, to advance theory and materials design

Los Alamos
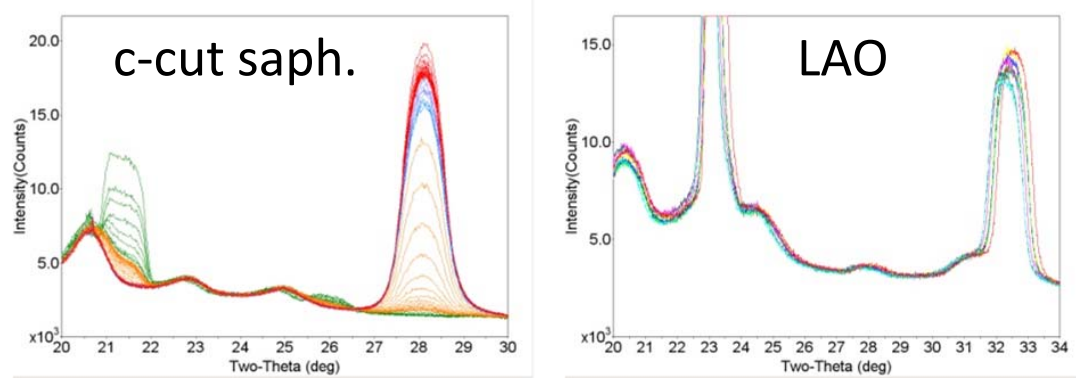

Control of $\mathrm{UO}_{2}$ oxidation via substrate choice (in-situ XRD studies).

- Synthesis and Characterization: Bauer, Holesinger, Jia, McCleskey, Scott

- Theory: Martin

- Electronic Structure: Joyce, Durakiewicz

- EXAFS/XANES: Conradson, Kozimor 